\title{
Properties of NGO 3\% Silicon Steel Asymmetrically Cold Rolled
}

\author{
Ramon Alves Botelho ${ }^{a}$, Saulo Brinco Diniz ${ }^{a}$, Marco Antonio da Cunha ${ }^{b}$, Luiz Paulo Brandao ${ }^{a}$ \\ ${ }^{a}$ Seção de Engenharia Mecânica e de Materiais, Instituto Militar de Engenharia, \\ Praça General Tibúrcio, 80, Urca, Rio de Janeiro, RJ, Brazil \\ ${ }^{b}$ Centro Universitário do Leste de Minas Gerais - UnilesteMG, \\ Avenida Tancredo Neves, 3500, Universitário, Coronel Fabriciano, MG, Brazil
}

Received: November 12, 2014; Revised: April 28, 2015

\begin{abstract}
The effects of asymmetric and conventional deformations and annealing on the microstructure of non-grain-oriented (NGO) $3 \mathrm{wt} \%$ silicon steel were analyzed by x-ray diffraction, optical microscopy and magnetometry. The results suggest that pure asymmetric rolling tends to lessen magnetic losses. However, intermediate annealing resulted in lower planar anisotropy, which could be estimated from the magnetic anisotropy theory. In this work, it was shown that this theory is able to predict the $\mathrm{J}_{50}$ magnetic polarization values using crystallographic texture.
\end{abstract}

Keywords: silicon steel, asymmetric rolling, magnetic anisotropy

\section{Introduction}

Electrical steels are widely used for electromagnetic purposes such as motors and transformers. Silicon is added to increase the electrical resistivity and to decrease the magnetic anisotropy. However, adding more than $3 \mathrm{wt} \%$ silicon makes the material harder and reduces workability ${ }^{1}$ and adding less than $2.5 \mathrm{wt} \%$ silicon leads to phase transformation. The main properties which affect the performance of electrical steels are grain size and crystallographic texture.

Nowadays, the manufacture of the silicon steel favors the crystallographic component (110)[001], which provides a high magnetic permeability in the rolling direction. However, the ideal texture that an electric steel should have for use in motor applications is the $\theta$-fiber $<001>/ /$ Normal Direction $(N D)$. The ideal grain size for non-grain oriented steels, in order to minimize magnetic losses, is 100 to $150 \mu \mathrm{m}^{[2]}$.

The manufacture process consists of rolling and annealing steps. In symmetrical rolling, the two cylinders have the same diameter, roughness and lubrication, while, in asymmetrical rolling, one or more of these variables are different ${ }^{3}$. The purpose of this work was to study the influence of asymmetrical cold rolling, with or without intermediate annealing, on the magnetic behavior of 3\% Si Non-Grain Oriented Steel (NGO) and to investigate the microstructure and crystallographic texture of the processed material.

\section{Experimental Procedure}

The study was conducted on sheets produced by Aperam South America (Brazil) as hot rolled plates $2.0 \mathrm{~mm}$ thick, $100 \mathrm{~mm}$ wide and $300 \mathrm{~mm}$ long. They were pickled with $20 \% \mathrm{HCl}+5 \% \mathrm{HF}+\mathrm{H}_{2} \mathrm{O}$ for 6 minutes before rolling.

The samples are labeled with uppercase letters. Samples labeled with three letters were submitted to two cold rolling steps and one intermediate annealing (I), where the first and the third letters mean the type of the first and second

*e-mail: brandao@ime.eb.br cold rolling steps, respectively. In the first step, the sample thickness was reduced from $2.0 \mathrm{~mm}$ to $0.6 \mathrm{~mm}(70 \%)$; in the second, the thickness was reduced to $0.5 \mathrm{~mm}(75 \%)^{[4]}$. Samples labeled with one uppercase letter were submitted to just one cold rolling step, where the thickness was reduced directly from $2.0 \mathrm{~mm}$ to $0.5 \mathrm{~mm}$. In all cases, A means asymmetric and $\mathrm{S}$ means symmetric rolling. The process was carried out on a FENN MFG. Co. D-51710:1973 rolling mill. For symmetric rolling, work cylinders with $133.7 \mathrm{~mm}$ in diameter were used; in the case of asymmetric rolling, the diameters of the top cylinder and of the bottom cylinder were $40.18 \mathrm{~mm}$ and $31.72 \mathrm{~mm}$, respectively.

The intermediate annealing was made in an atmosphere of $100 \% \mathrm{~N}_{2}$, at $640{ }^{\circ} \mathrm{C}$, with a dew point lower than $-30{ }^{\circ} \mathrm{C}$, at $1.2 \mathrm{~m} / \mathrm{min}$ cooling rate, for $60 \mathrm{~s}$, in a continuous furnace. The final annealing was performed in an atmosphere of $24 \% \mathrm{~N}_{2} / 76 \% \mathrm{H}_{2}$, at $1030{ }^{\circ} \mathrm{C}$, with a dew point lower than $-20{ }^{\circ} \mathrm{C}$, at $1.4 \mathrm{~m} / \mathrm{min}$, for $60 \mathrm{~s}$, in the same furnace.

Samples were mechanically ground with 500 and 600 grit paper and chemically polished in $5 \% \mathrm{HF}+\mathrm{H}_{2} \mathrm{O}_{2}$ for $20 \mathrm{~s}$ for crystallographic texture analysis and polished with diamond suspension from 6 to $1 \mu \mathrm{m}$ and etched by Nital $5 \%$ for $7 \mathrm{~s}$ for optical microscopy. The grain sizes of the samples were evaluated by the Heyn linear intercept process ${ }^{5}$.

The evaluation of the crystallographic texture of the samples was made in a PANalyticalX'Pert PRO MRD diffractometer using $\mathrm{CoK} \alpha$ radiation measuring (110), (200) and (211) pole figures. The orientation distribution functions $(\mathrm{ODF})^{6}$ were calculated with the help of the popLA software. The magnetic properties were measured in a Brockhaus MPG 100D measurer by single sheet and Epstein frame tests, which can compute the iron losses at $1500 \mathrm{mT}$ and $60 \mathrm{~Hz}\left(P_{15 / 60}\right)$, and also magnetic permeability $(\mu)$ and polarization $\left(\mathrm{J}_{50}\right)$.

The magnetic anisotropy model ${ }^{7,8}$ can be used to estimate magnetic polarization $\left(\mathrm{J}_{50}\right)$ from crystallographic texture in electrical steels ${ }^{9}$. The model defines that there is an energy necessary to orientate the grains in one preferred direction, 
called Energy of Anisotropy $\left(\mathrm{E}_{\mathrm{a}}\right)$. For silicon steels, the preferred orientation of the magnetization is [100]. The energy needed to magnetize the grains in this direction depends on the silicon content of the material and on the texture of the sheet, which can be expressed by a parameter called Energy of Anisotropy Factor (fEa) 7 . The magnetic polarization $\mathrm{J}_{50}{ }^{6}$ can be estimated using Equations 1-7, where fEa is an average depending on the direction cosines $\left(\alpha_{1} \alpha_{2} \alpha_{3}\right)$ of the magnetization with respect to the cube axes and carries the texture contribution to the model ${ }^{10}$. In these equations, $f(g)$ are the crystallographic component intensities calculated by the $\mathrm{ODFs}^{6}, K_{1}$ and $K_{2}$ are anisotropy coefficients ${ }^{11}$ of the material, $J_{S}$ is the saturation magnetization ${ }^{11}$ and $C_{\mathrm{Si}}$ is the Si content in $\mathrm{wt} \%$. The constants $c_{1}$ and $\mathrm{c}_{2}$ are defined and described by Yonamine et al. ${ }^{2}$. The second term of Equation 5 is much smaller than the first and, consequently, may be neglected.

$J_{50}(T)=c_{1}-c_{2} \times(E a)$

$c_{1}=19,1706-17,08346 \times J_{s}+4,24696 \times J_{s}^{2}$

$c_{2}=22,20874-20,27905 \times J_{s}+4,70645 \times J_{s}{ }^{2}$

$J_{s}(T)=2,16-0,048 \times C_{S i}$

$$
\begin{aligned}
& E a=K_{1} \times f E a+K_{2} \times\left(\alpha_{1}^{2} \cdot \alpha_{2}^{2} \cdot \alpha_{3}^{2}\right) \\
& K_{1}\left(J / m^{3}\right)=\left(5,2-0,5 \times C_{S i}\right) \times 10^{4} \\
& f E a=\left(\alpha_{1}^{2} \alpha_{2}^{2}+\alpha_{1}^{2} \alpha_{3}^{2}+\alpha_{2}^{2} \alpha_{3}^{2}\right) \times f(g)
\end{aligned}
$$

\section{Results}

The fact that grain sizes measured by the Heyn linear intercept procedure ${ }^{5}$, about $107 \pm 5 \mu \mathrm{m}$, were almost the same for all samples means that grain size is not very sensitive to the different processes used in this work. Microscopic analysis confirmed that there was no recrystallization after the intermediate annealing, which showed elongated grains along the rolling direction, but equiaxed grains were observed after the final annealing.

The crystallographic texture was calculated by the orientation distribution function (ODF) and the results are shown in Figures 1 and 2. Their main components were highlighted using the following notation: $C_{R P}$ is the Rotated Cube (100)[011], $C$ is the Cube (100)[001], $C_{T P}$ is the Turned Cube (100)[031], $G$ is the Goss component (100)[001], $\alpha$-fiber is $<110>/ / \mathrm{RD}, \eta$-fiber is $<100>/ / \mathrm{RD}, \zeta$-fiber is $<110>/ / \mathrm{ND}$,

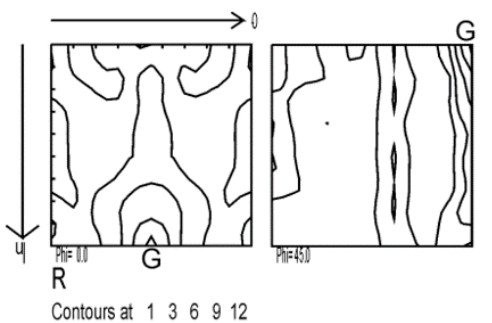

(a)

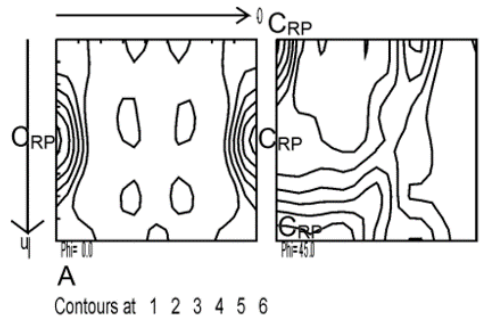

(b)

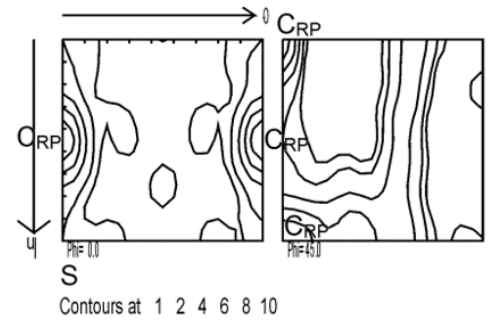

(c)

Figure 1. ODFs of (a) hot rolled sample as received, (b) asymmetrical and (c) symmetrical samples after intermediate annealing.

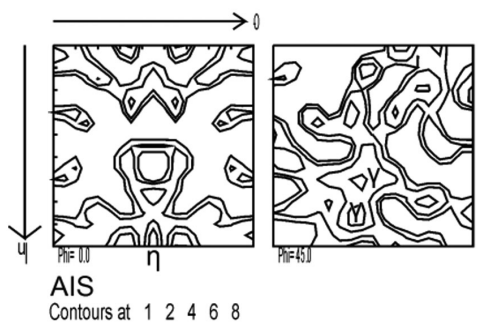

(a)

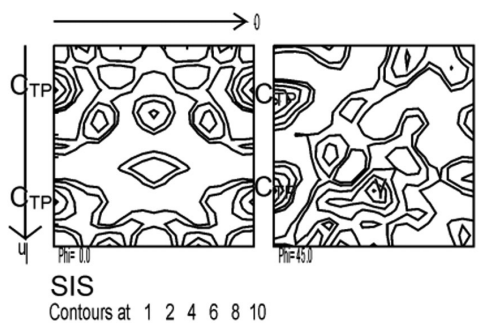

(d)

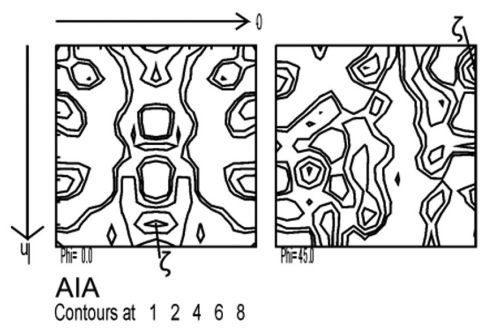

(b)

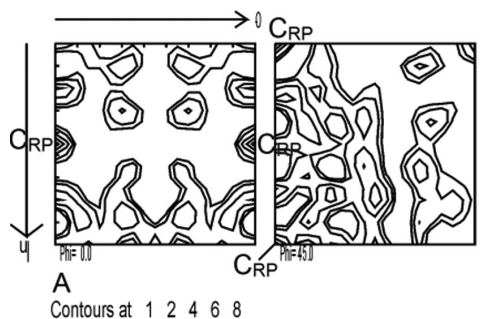

(e)

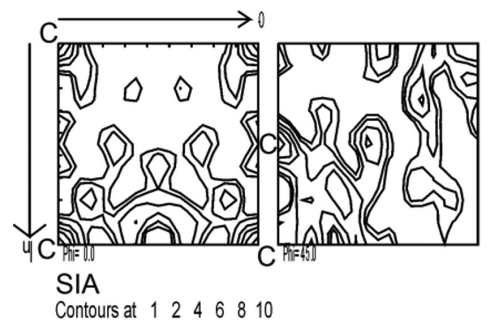

(c)

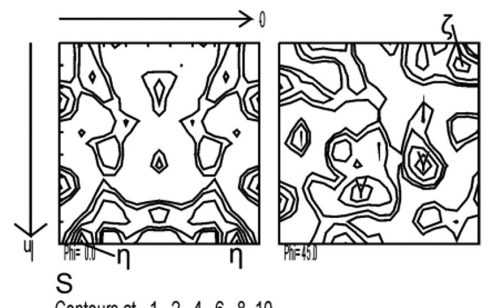

(f)

Figure 2. ODFs of final annealing texture of $(a, d)$ symmetrical and $(b, c)$ asymmetrical second cold rolling step samples, measured on half-thickness position, and of the one cold rolling step samples: (e) A and (f) S. 
$\gamma$-fiber is $<111>/ / \mathrm{ND}$, and $\theta$-fiber is $<100>/ / \mathrm{ND}$, where $R D$ means rolling direction and $N D$ means normal direction.

The hot rolled as-received sheets already have a high intensity of the Goss component, as seen in Figure 1a, where can also be noticed that the intermediate annealing process favors the $C_{R P}$ component in both symmetrically and asymmetrically rolled samples (Figures $1 \mathrm{~b}-\mathrm{c}$ ). The $C_{R P}$ component belongs to $\theta$-fiber, the best for NGO steels.

Figure 2 shows the texture after the final annealing process for all samples. For those with first asymmetrical rolling (Figures 2a-b), the AIS material presents better results due to the higher intensity of the Cube component $(C)$, but the $\zeta$-fiber is also good for electrical steels. For those first rolled symmetrically (Figures $2 \mathrm{c}-\mathrm{d}$ ), the SIS sample shows most attractive texture, since it has a higher $C_{T P}$ although it also has a higher $\gamma$-fiber. The most pronounced texture is that of A and S samples, shown in Figures 2e-f, where it is remarkable that the first has the $C_{R P}$ intensity greater than the second, which still has $\gamma$-fiber.

Based on the crystallographic texture, the polarization $\mathrm{J}_{50}$ can, finally, be calculated using Equations 1-7. The experimental and calculated results of magnetic polarization $\left(\mathrm{J}_{50}\right)$ are shown in Table 1 . This table also shows $P_{15 / 60}$, the most important loss for common applications. Confidence intervals were calculated using the t-Student distribution, for a $95 \%$ confidence level.

\section{Discussion}

The evolution of the crystallographic texture in the samples is shown in Table 2. Symmetrical rolling encouraged the formation of $\theta$-fiber during the intermediate annealing step, which also favored the growth of shear band $(E)(111)$ [110] and $\gamma$-fiber, harmful to electrical steels, but increased the Cube component $(C)$.

The final annealing affected the samples in many ways, and so, for easier understanding, each component will be treated separately. The $\theta$-fiber was strongest for the one-step symmetrical rolled samples (SIS and S). The Cube and $\eta$-fiber increased in all sheets, but the strongest values could be found in SIA, while the rotated Cube $\left(C_{R P}\right)$ decreased in almost all samples, but remained strong for A. The Goss component $(G)$, very important for NGO steels, was intensified in AIA and A samples, probably due to migration of this component during the annealing, but was absent in alternated rolled samples (AIS and SIA) and in $\mathrm{S}^{12}$. The rotated Goss $\left(G_{R}\right)$ component could only be found in AIA and SIS samples, being strongest in the first. The final annealing eliminates the shear bands $(E)$, but not the $\gamma$-fiber for the asymmetrical rolled samples (AIA, SIA and A).

Asymmetrical cold rolled samples achieved more favorable values of $\mathrm{J}_{50}$ (Table 1) in the magnetic analyses, where AIA reached the highest value. It can be seen that the symmetrically cold rolled samples have $\mathrm{J}_{50}$ values similar to the asymmetrically rolled ones, probably due to its low fEa.

As mentioned, the $\mathrm{J}_{50}$ values can be estimated from the fEa values, which are calculated from the crystallographic texture of the materials. Figure 3 shows that experimental and calculated values of $\mathrm{J}_{50}$ have a good correlation $\left(\mathrm{R}^{2}\right)$, about 0.9945 ; it can thus be suggested that the polarization can be pretty well estimated by using fEa values when no

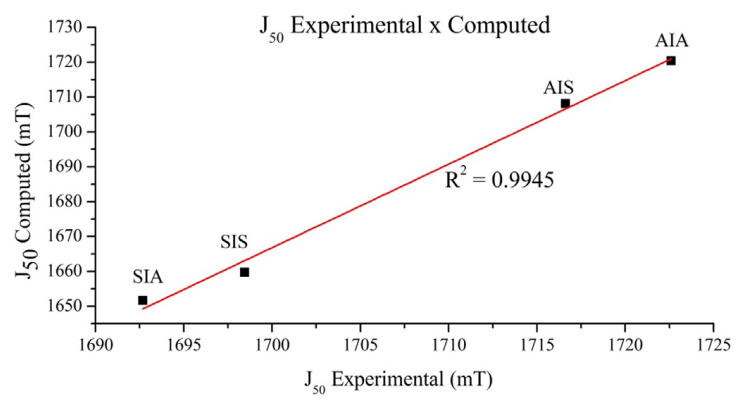

Figure 3. Experimental and computed $\mathrm{J}_{50}$ values for samples rolled in two steps.

Table 1. Experimental values of magnetic loss, $\mathrm{P}_{15 / 60}$, and $\mathrm{J}_{50} *$ for rolling direction $\left(0^{\circ}\right)$ and calculated values of fEa and $\mathrm{J}_{50} * *$.

\begin{tabular}{ccccccc}
\hline & AIA & AIS & SIS & SIA & A & S \\
\hline $\mathrm{P}_{15 / 60}(\mathrm{~W} / \mathrm{Kg})$ & $2.79 \pm 0.24$ & $2.81 \pm 0.12$ & $2.83 \pm 0.19$ & $2.99 \pm 0.04$ & $2.66 \pm 0.06$ & $2.69 \pm 0.07$ \\
$\mathrm{fEa} 0^{\circ}$ & 0.161 & 0.168 & 0.197 & 0.202 & 0.099 & 0.028 \\
$\mathrm{~J}_{50} *(\mathrm{mT})$ & $1722.6 \pm 1.18$ & $1716.6 \pm 1.98$ & $1698.5 \pm 2.06$ & $1692.7 \pm 3.18$ & $1717.7 \pm 3.72$ & $1721.5 \pm 2.92$ \\
$\mathrm{~J}_{50} * *(\mathrm{mT})$ & 1720.395 & 1708.122 & 1659.702 & 1651.632 & 1825.306 & 1944.002 \\
\hline $\mathrm{K}$ is taken to be $3.7 \times 10^{4} \mathrm{~J} / \mathrm{m}^{3}$ for all samples. * J experimental. ** J computed. & & &
\end{tabular}

Table 2. Crystallographic texture of samples after intermediate and final annealing.

\begin{tabular}{ccccccccccc}
\hline \multicolumn{4}{c}{} & \multicolumn{1}{c}{ INTERMEDIATE ANNEALING } & \multicolumn{7}{c}{ FINAL ANNEALING } \\
\hline & AIA & AIS & SIS & SIA & AIA & AIS & SIS & SIA & A & S \\
\hline $\mathrm{C}$ & 1.7 & 2.5 & 2.7 & 2.0 & 4.8 & 3.9 & 0.0 & 11.8 & 4.0 & 0.0 \\
$\mathrm{G}$ & 1.1 & 1.8 & 0.5 & 0.3 & 2.0 & 0.0 & 0.0 & 0.0 & 5.6 & 0.0 \\
$\mathrm{C}_{\mathrm{TP}}$ & 6.4 & 9.9 & 13.5 & 9.8 & 0.6 & 0.0 & 2.4 & 1.9 & 9.3 & 0.0 \\
$\mathrm{E}$ & 2.6 & 5.1 & 5.3 & 5.2 & 0.0 & 4.5 & 0.0 & 0.0 & 0.0 & 0.0 \\
$\mathrm{G}_{\mathrm{R}}$ & 0.5 & 0.6 & 0.6 & 1.1 & 0.6 & 0.0 & 1.4 & 0.0 & 0.1 & 0.0 \\
$\eta$-fiber & 1.9 & 2.6 & 2.7 & 2.0 & 4.8 & 8.1 & 8.5 & 11.8 & 4.0 & 10.7 \\
$\theta$-fiber & 6.4 & 9.9 & 13.5 & 10.0 & 5.4 & 4.6 & 8.7 & 11.9 & 9.3 & 6.5 \\
$\gamma$-fiber & 2.6 & 5.1 & 5.3 & 5.2 & 1.1 & 5.0 & 5.2 & 0.1 & 0.0 & 1.1 \\
\hline
\end{tabular}

Captions: $\mathrm{C}\{100\}<100>$; $\mathrm{G}\{110\}<100>; \mathrm{C}_{\mathrm{TP}}\{100\}<110>$; $\mathrm{E}\{111\}<110>; \mathrm{G}_{\mathrm{R}}\{110\}<110>$. 
magnetic tests are available. The statistical one-way variance analysis (ANOVA) may also support that conclusion, since the P-value is larger than 0.05 . For this fitting, only data of samples that were submitted to intermediate annealing were used, since they underwent the same heat treatment, which was quite different for the A and S materials. The crystallographic texture can be used to calculate the $\mathrm{J}_{50}$ in others directions besides the cold rolling direction,

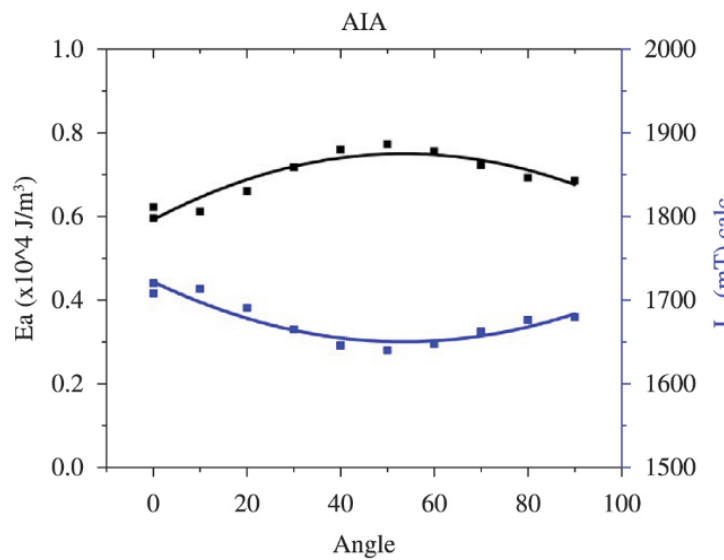

(a)

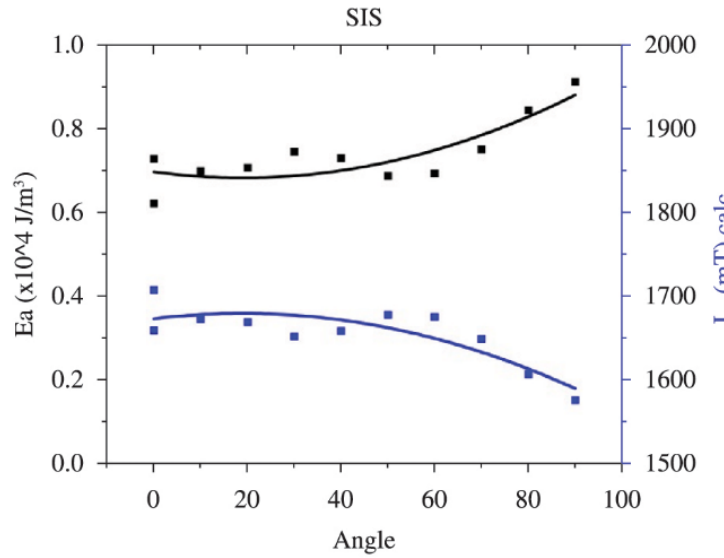

(c)

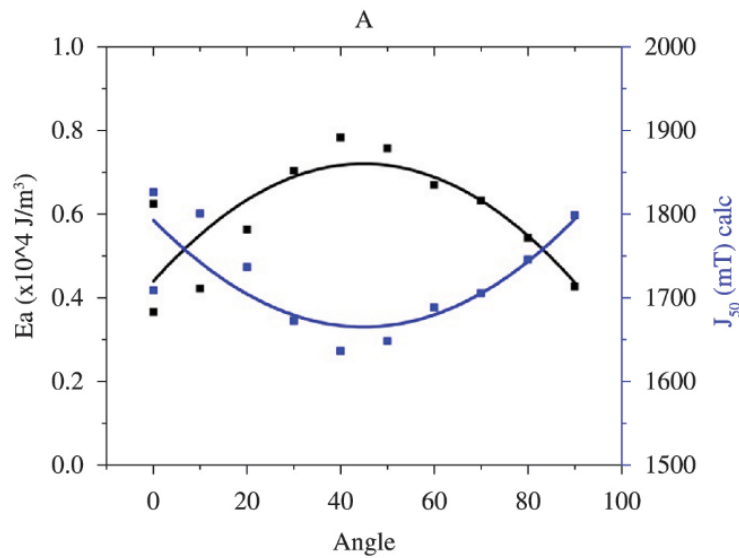

(e) leading to a better understanding of the behavior of alternate electric currents in sheets of electric steel, for example. These analyses are described in the graphs of Figure 4.

The highest value of $\mathrm{J}_{50}$ was obtained on the rolling direction $\left(0^{\circ}\right)$ for all samples. It is quite possible that an incomplete recrystallization of the SIS sample interrupted the Cube component growth on the surface and therefore this material presented a high polarization at $50^{\circ}$. Based on

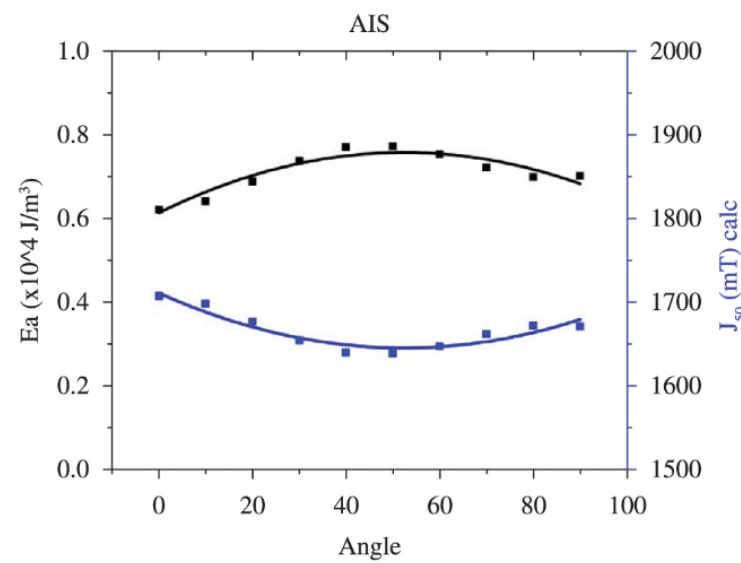

(b)

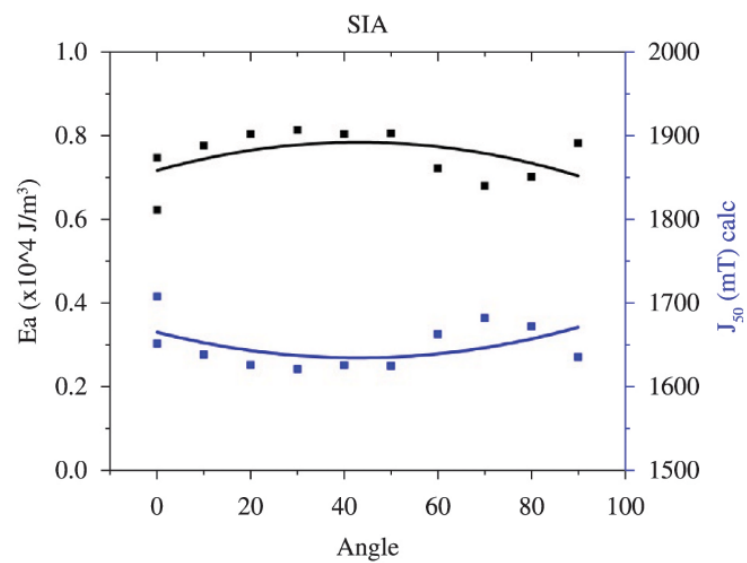

(d)

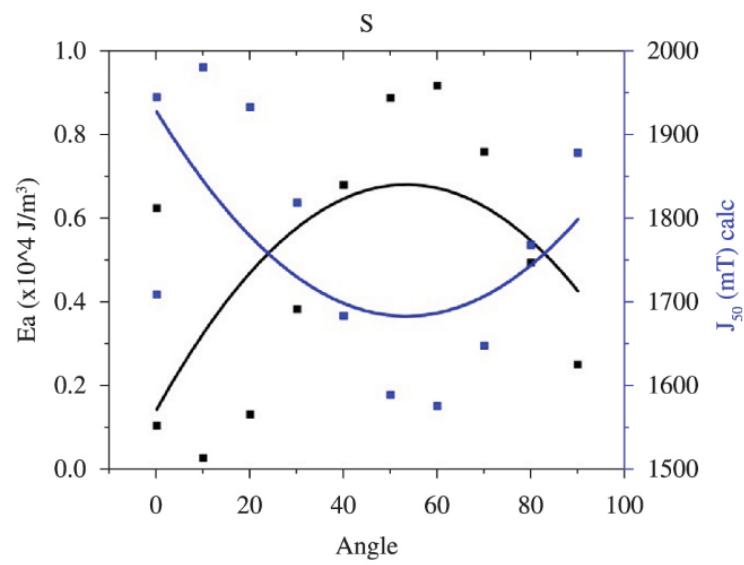

(f)

$\mathrm{Ea}\left(\mathrm{x} 10^{\wedge} 4 \mathrm{~J} / \mathrm{m}^{3}\right) \quad \square \mathrm{J}_{50}(\mathrm{mT})$ calc

Figure 4. $\mathrm{J}_{50}$ as a function of the rolling direction. 
Figures $4 \mathrm{a}, \mathrm{b}$ and $\mathrm{e}$, it is possible to conclude that the grain structure and the crystallographic texture resulting from asymmetrical rolling remain unchanged even if the sheets are submitted subsequently to others thermomechanical treatments ${ }^{13}$. Asymmetric cold rolling also led to a lower planar anisotropy than symmetrical rolling (Figures $4 \mathrm{e}-\mathrm{f}$ ). However, symmetric cold rolling in two steps also reduced the planar anisotropy of the samples (Figure $4 \mathrm{c})^{14}$.

\section{Conclusions}

- The anisotropy of the material can be estimated by the use of the magnetic anisotropy theory ${ }^{7}$, which considers simultaneously all the texture components present in the sample. This theory may also be used to predict the magnetic polarization, since there is a good correlation between the calculated and the experimental values of $\mathrm{J}_{50}$;

\section{References}

1. Cardoso RFA. Influência do tamanho de grão e das adições de Al e Mn nas propriedades magnéticas dos aços elétricos de grão não orientado com 3\%Si. [Dissertation]. Rio de Janeiro: Instituto Militar de Engenharia; 2005.

2. Landgraf FJ, Takanohashi R and Campos MF. Tamanho de grão e textura dos aços elétricos de grão não-orientado. In: Workshop Sobre Textura e Relações de Orientação: Deformação Plástica, Recristalização, Crescimento de Grão; 2001; São Paulo. São Paulo; 2001.

3. Ji YH and Park JJ. Development of severe plastic deformation by various asymmetric rolling processes. Materials Science and Engineering A. 2009; 499(1-2):14-17. http://dx.doi.org/10.1016/j. msea.2007.11.099.

4. Takashima M, Komatsubara M and Morito N. $\{001\}<210>$ texture development by two-stage cold rolling method in non-oriented electrical steel. ISIJ International. 1997; 37(12):1263-1268. http://dx.doi.org/10.2355/isijinternational.37.1263.

5. American Society for Testing and Materials - ASTM. E112-10: Standard test methods for determining average grain size. West Conshohocken; 2010.

6. Roe R-J. Description of crystallite orientation in polycrystalline materials: III. General solution to pole figure inversion. Journal of Applied Physics. 1965; 36(6):2024-2031. http://dx.doi. org/10.1063/1.1714396.

7. Cunha MA and Luna PC. Use of EBSD in the study of magnetic anisotropy of silicon steel. Acta Microscopica. 1999; 8(Suppl A):289-290.
- The results show that intermediate annealing favored the formation of $\theta$ and $\gamma$ fibers in symmetrically cold rolled samples, while the final annealing favored the growth of Goss and Cube components in the A sample;

- Two-step symmetrical cold rolling reduced the planar anisotropy of the samples and the results suggest that once a sample is asymmetrically rolled, its crystallographic texture and grain structure will remain unchanged even if other thermomechanical treatments are subsequently applied ${ }^{13}$.

\section{Acknowledgements}

The authors thank CAPES and CNPq for financial support and Aperam South America Co. for technical support and magnetic testing.

8. Yonamine T, Campos MF, Castro NA and Landgraf FJG. Modelling magnetic polarization $\mathrm{J}_{50}$ by different methods. Journal of Magnetism and Magnetic Materials. 2006; 304(2):e589-e592. http://dx.doi.org/10.1016/j.jmmm.2006.02.184.

9. Cunha MA and Paolinelli SC. Effect of the annealing temperature on the structure and magnetic properties of $3 \%$ Si non-oriented steel. Journal of Magnetism and Magnetic Materials. 2003; 254-255:379-381. http://dx.doi.org/10.1016/ S0304-8853(02)00912-5.

10. Bunge H-J. Texture analysis in materials science: mathematical methods. London: Butterworth-Heinemann; 1982. 593 p.

11. Matsumura K and Fukuda R. Recent developments of non-oriented electrical steel sheets. IEEE Transactions on Magnetics. 1984; 20(5):1533-1538. http://dx.doi.org/10.1109/ TMAG.1984.1063223.

12. Xiuhua G, Kemin Q and Chunlin Q. Magnetic properties of grain oriented ultra-thin silicon steel sheets processed by conventional rolling and cross shear rolling. Materials Science and Engineering A. 2006; 430(1-2):138-141. http://dx.doi. org/10.1016/j.msea.2006.05.058.

13. Sha YH, Zhang F, Zhou SC, Pei W and Zuo L. Improvement of recrystallization texture and magnetic property in non-oriented silicone steel by asymmetric rolling. Journal of Magnetism and Magnetic Materials. 2008; 320(3-4):393-396. http://dx.doi. org/10.1016/j.jmmm.2007.06.026.

14. Honda A, Sato K and Ohyama I. Effects of core materials on efficiency of inverter drive motor. Kawasaki Steel Technical Report. 1998; 39:36-40. 